\title{
The critical factors for cloud computing adoption during SARS-CoV-2 pandemic
}

\author{
Rodolfo D. Vareschi, ISEG - University of Lisbon, Portugal, \\ rodolfovareschi@gmail.com
}

Winnie Ng Picoto, ISEG - University of Lisbon, Portugal, w.picoto@iseg.ulisboa.pt

\begin{abstract}
Due to the rapid global spread of the pandemic caused by the new coronavirus, companies and institutions adopted precautionary measures to reduce the risk of contagion, such as asking employees to work remotely from their homes. In this scenario, cloud computing technology has proven to be a great ally of companies to overcome the crisis caused by the pandemic as it provides the necessary infrastructure to access the organizational systems and resources from anyplace, anywhere, and anytime. Although current research identifies important factors for cloud computing adoption, none has yet analyzed whether those are the same given the crisis cause by the pandemic. For this purpose, 18 factors were identified and presented to experts in cloud computing technology, to seek a consensus regarding the order of importance of these factors. Using the Delphi method conducted with two rounds of questions, an ordered list according to the degree of importance of the main factors that influence the adoption of cloud computing was obtained. According to the results, the six most important factors are: (1) adoption, migration, and acquisition cost; (2) availability and accessibility; (3) scalability; (4) cost of data confidentiality and availability loss; (5) security, and (6) customization.
\end{abstract}

Keywords: Cloud computing, SARS-CoV-2, technology adoption, Delphi methodology.

\section{Introduction}

In December 2019, a series of pneumonia cases of unknown cause were reported in Wuhan, China's Hubei province, with clinical presentations very similar to viral pneumonia. Analysis of patients' respiratory tract samples indicated infection with a new type of coronavirus, called 2019-nCoV (Huang et al., 2020). After rapidly spreading around the world, the World Health Organization (WHO) declared the new coronavirus a pandemic, which affected at least 220 countries and territories, with the United States of America, India, Brazil, Russia, and the United Kingdom being the countries with the highest number of cases of infection (Worldmeters, 2021). On January 10, 2021, a total number of 88,383,771 confirmed positive cases led to the death of more than 1,919,126 people (WHO, 2021). Over the months, while the virus spread around the world, China adopted harsh measures of confinement and social distancing, thus managing to reduce to zero the number of cases of local transmission. The success of the distance and social confinement measures adopted by China, as well as strongly recommended by WHO, has encouraged governments in many other countries to take the similar measures (Melo et al., 2021). In a short time, some 80 countries and territories around the world enacted measures to restrict activities and promote social distance. As a result, more than 3.4 billion people remained confined, which resulted in a significant economic and social impact on a global level (Bouziri et al., 2020).

The United Nations Educational, Scientific and Cultural Organization (UNESCO) reported in April 2020, that educational institutions were closed in 185 countries, affecting 1,542,412,000 
students, representing $89.4 \%$ of the total number of students enrolled, and that only during May, some countries, with decreasing numbers of cases and deaths, managed to suspend the confinement measures and gradually resume school activities (Marinoni et al., 2020). It is important to note that these school breaks will not only be a short-term problem, but they can also have long-term consequences and are likely to increase economic and social inequalities (Burgess \& Sievertesen, 2020). In fact, in recent years the Internet has accelerated the use of cloud services to support the online education system. Cloud computing has become the main means to enable these services, providing facilities to users with the potential to offer new opportunities for improvement and innovation (Sultan, 2010). During the crisis caused by the new coronavirus pandemic, not only educational institutions, but several other organizations sought to adopt alternative measures to face-to-face activities, which generated a greater demand for cloud service providers, since almost all sectors were "forced" to electronically convert their services for the continuation of their activities (Alashhab et al., 2021).

Cloud computing technology has important attractive features in a scenario like the one above. Its architecture is market-oriented, since, unlike a resource management architecture centered on the traditional system (on-premises), the cloud-based architecture is regulated by the supply and demand of market-balanced cloud resources (Buyya et al., 2008). Another advantage of this technology is its flexibility, that is, a service can easily be expanded or reduced in terms of resources for optimal use (Vaquero et al., 2009). In addition, the ability to self-serve in relation to the provision of computational resources and the possibility of paying only for the resources used are characteristics that are highly appreciated by information technology managers, (Leavitt, 2009). It is also worth mentioning that cloud computing changes the way organizations manage their Information Technology (IT) resources, challenges traditional governance approaches and often requires organizations to adjust their processes (Armbrust et al., 2010). In general, cloud computing presents opportunities and challenges for organizations and IT professionals. Some of these challenges are technical, which can be solved over time, while others are related to the uncertainties derived from being involved with a recent innovation (Lin \& Chen, 2012). In the last decade, IT researchers have applied several economic, strategic, organizational, and social theories in an attempt to identify the main drivers for the adoption of cloud computing technology by organizations (Schneider \& Sunyaev, 2016). Considering the current worldwide pandemic crisis caused by the new coronavirus and the possibilities offered by cloud computing technology, the importance of factors that influence cloud computing adoption could have changed and to our knowledge that has not been investigated yet. Thus, this study addresses the following research questions: (1) What are the most relevant factors for the decision of cloud computing adoption in organizations in the current pandemic of the new coronavirus? (2) How does the pandemic crisis impact cloud computing adoption? Therefore, this work aims to contribute to a better understanding and discussion about the adoption of cloud computing by organizations at this time of pandemic crisis, considering the cloud adoption factors and their categories proposed by Ray (2016) although it is not a comparative study. This study contributes to the research by enhancing the understanding of important factors affecting cloud computing adoption during periods of crises. It also has practical some contributions as it supports organizations in planning their cloud computing adoption strategies not only during the recent coronavirus pandemic, but also on future crisis, by identifying the critical factors for the adoption of such technology.

This paper is structured as follows: first it presents the concepts of cloud computing, cloud computing services and cloud computing deployment models, and then the technology acceptance theories that are important to understand a cloud computing adoption and the factors 
that influence it. Then, the application of the Delphi method is explained, and results are presented and discussed. Finally, a conclusion about the observed results is presented.

\section{Literature Review}

While cloud computing is a convenient model for organizations to meet their computing requirements, studies show that there are different factors that drive the adoption of cloud computing. Some of these factors include cost savings, increased service reliability, collaboration and sharing, disaster prevention, data security and regulatory compliance (Low, Chen \& Wu, 2011). According to Gupta (2013), the factors that affect the adoption of cloud computing permeate technological, organizational, and environmental contexts. These three contexts involve stakeholders that include, but are not limited to: cloud service providers, end users, corporate leaders, regulatory authorities, and competitors in the marketplace. Prior to the discussion about the main factors of adoption of cloud computing, it is necessary to present some concepts and definitions regarding this technology.

\section{Cloud Computing}

Cloud computing represents the way in which IT services are provided over the Internet through a virtual and scalable infrastructure, enabling the user to access shared resources in a service format adapted to their needs, without having to buy, install, maintain, or manage these computing resources (Garrison et al., 2015). Different cloud computing definitions are available in the literature. Traditionally, the definition given by the National Institute of Standards and Technology (NIST) is adopted, which defines cloud computing as a model "for enabling ubiquitous, convenient, on-demand network access to a shared pool of configurable computing resources (e.g., networks, servers, storage, applications, and services) that can be rapidly provisioned and released with minimal management effort or service provider interaction" (Mell \& Grance, 2011, p. 2). In addition, cloud computing has five essential characteristics: On-demand self-service, Broad network access, Resource pooling (location independence), Rapid elasticity, and Measured service (Mell \& Grance, 2011). A study carried out by the International Data Corporation (IDC), found that even during the pandemic, the expectation of growth in investment in annual digital transformation is $15.5 \%$ from 2020 to 2023 , in an approximate value of USD \$6.8 trillion (Fitzgerald et al., 2020). In a publication, the Gartner Institute (2020) reports that IT investments are expected to accelerate further after the pandemic, with cloud computing accounting for $14.2 \%$ of total corporate IT spending in 2024, up from $9.1 \%$ in 2020, and that spending by end users worldwide on public cloud services is expected to grow by $18.4 \%$ in 2021 , totaling $\$ 304.9$ billion, against $\$ 257.5$ billion in 2020 . To better understand the adoption of this technology, it is necessary to discuss its different services and models.

\section{Cloud Computing Services}

Cloud computing service models refer to the types of services that can be obtained in the cloud. The delivery of cloud services is divided into three different models (Pardeshi, 2014).

\section{Infrastructure as a Service (IaaS)}

Infrastructure as a Service (IaaS) providers offer storage, networking, virtualization processing, among other computing resources through which the customers can deploy and run applications (Mell \& Grance, 2011). According to Hou (2021), IaaS presents to cloud users alternatives to the local infrastructure, avoiding investments in hardware, which can be underused, which would allow a possible reduction in costs with continuous maintenance, as users only pay for the use or provisioning of the services needed to their applications. The main advantages and characteristics of IaaS are cost reduction, as it would no longer be necessary to 
maintain the local infrastructure, which would require a greater investment in maintenance and qualified labor; flexibility and scalability, because allows to update and increase the infrastructure whenever it is necessary; greater security, as service providers ensure welldefined security protocols and updates; better control, allowing to know exactly how much is being consumed from the infrastructure. Some examples of IaaS are Rackspace, Google Compute Engine (GCE), and Amazon Web Services EC2 (Armbrust et al., 2010).

\section{Platform as a Service (PaaS)}

Platform as a Service (PaaS) providers offer to customers the ability to deploy acquired or developed applications to the cloud infrastructure, using programming languages, libraries, services, and tools supported by the provider. The consumer has control over the deployed applications and configuration settings for the application's hosting environment although the provider manages the infrastructure (Mell \& Grance, 2011). According to Hou (2021), PaaS solution provides the platform for developers to create exclusive and customizable software, so it is the most cost-effective and time-efficient way for a developer to create an application. The main advantages and characteristics of PaaS are scalability, ability to increase the necessary infrastructure; simplicity, easy to operate without extensive knowledge of system administration; virtualized, built on virtualization technology. Some examples of PaaS are AWS Elastic Beanstalk, Google Application Engine, and Microsoft Azure (Armbrust et al., 2010).

\section{Software as a Service (SaaS)}

In Software as a Service (SaaS), the customers use a web browser to access an application developed, provided, and maintained by third parties, usually for a monthly subscription fee. The consumer does not manage or control infrastructure services such as the network, servers, operating systems, storage or even resources of the applications, except for a few configurations of the application itself, such as specific user configurations (Mell \& Grance, 2011). According to Hou (2021), with SaaS, it is no longer necessary to install and run software applications on your computer, everything is available on the Internet when you access your online account. The main advantages and characteristics of SaaS are the availability via the Internet, no software installation required; management, as maintenance is done by the service provider; ready to use; safe and convenient, maintenance is part of the cost. Some examples of SaaS are Gmail, DropBox, Microsoft 365, and SalesForce (Armbrust et al., 2010).

\section{Cloud Computing Deployment Models}

According to the existing literature, there are four cloud deployment models: Public cloud, Private cloud, Hybrid cloud, and Community cloud (Pardeshi, 2014).

\section{Public cloud}

Public cloud means that all hardware (server and storage), software, and other supporting infrastructure are owned and managed by the cloud provider and delivered over the Internet (Mell \& Grance, 2011). In a public cloud, the infrastructure is shared with other organizations and/ or users, who through their web browsers access and manage their accounts and services. Public cloud deployments are often used to provide web-based email, online office applications, storage, and test and development environments (Microsoft Azure, 2021). The advantages of the public cloud are costs reduction, there is no need to buy hardware or software; reliability, a large network of servers protects against failures; scalability, on-demand features are available to meet business needs whenever is necessary. Some examples of public cloud are Alibaba Cloud, Amazon Cloud (AWS), IBM Cloud, Oracle Cloud, and Microsoft Azure (Hou, 2021; Mell \& Grance, 2011; Microsoft Azure, 2021). 


\section{Private cloud}

In Private cloud, the cloud infrastructure is of exclusive use by a single organization, and can be owned and managed, by the organization itself, or by third parties or by a combination of them (Mell \& Grance, 2011). Private cloud can be physically located in the organization's onsite datacenter, or it can be hosted by a third-party service provider. Services and infrastructure are always maintained on a private network, with hardware and software dedicated exclusively to the organization itself (Microsoft Azure, 2021). The main advantages of the private cloud are flexibility, ability to customize the cloud environment to meet specific business needs; better control, resources are not shared with others, so higher levels of control and privacy are possible; scalability, often offer more scalability when compared to local infrastructure. Some examples of private cloud are Azure Stack, Open Shift, and Open Stack (Hou, 2021; Mell, \& Grance, 2011; Microsoft Azure, 2021).

\section{Hybrid cloud}

In Hybrid cloud, the infrastructure is composed by two or more distinct cloud infrastructures (private, community or public). It belongs to the entity itself and is interconnected by standardized or proprietary technologies, which allows the portability of data and applications (Mell \& Grance, 2011). If computer service's needs, such as processing capacity, change over time, hybrid cloud computing allows to resize the local infrastructure to the public cloud, preventing a breakdown of the applications that are running. The main advantages of the hybrid cloud are better control, the organization can maintain a private infrastructure for confidential assets or workloads that require low latency; flexibility, allows to benefit from additional cloud computing resources in the public cloud when they are needed; cost reduction, with the ability to scale to the public cloud, paying for extra computing power only when is needed (Hou, 2021; Mell, \& Grance, 2011; Microsoft Azure, 2021).

\section{Community cloud}

In community cloud, the cloud infrastructure is exclusive of a community of consumers who share the same concerns and interests. It can be owned, managed, and operated by one or more organizations in the community, a third party, or some combination of them, and it can exist inside or outside the organization facilities (Mell \& Grance, 2011). According to Goyal (2014), community cloud is like a private cloud, but the infrastructure and computing resources are shared exclusively between two or more organizations that have common privacy, security, and regulatory concerns. The main advantages of the community cloud are better cost savings due to sharing the infrastructure with partner organizations; flexibility, greater flexibility compared to own infrastructure (Hou, 2021; Mell, \& Grance, 2011; Microsoft Azure, 2021).

\section{Technology Acceptance}

After defining the concepts of cloud computing services and their deployment models, it is necessary to understand what makes a technology accepted by users or organizations. The acceptance of a new technology by users or by an organization depends mainly on the perception of how that technology can help them to accomplish tasks in a faster and more efficient way. Several frameworks have been proposed to assist in studies on the adoption of innovations in information technology, some of the most used, according to Oliveira and Martins (2011), are:

Diffusion of Innovations (DoI) - The theory explains how innovation is acceptable to users, how it is disseminated, and to what extent it is acceptable at the individual and business level. Furthermore, according to this theory, innovation is transmitted through certain channels over time and within a specific social system. Individuals show different degrees of willingness to 
adopt innovations, observing a normal statistical distribution of acceptance over time (Rogers, 1995).

Technology Acceptance Model (TAM) - The model predicts the technology acceptance and explains the difference in consumer behavior when it comes to adopting new technologies at work (Davis, 1989).

Technology - Organization - Environment (TOE) - The framework identifies three aspects of a company's context that influence the process by which it adopts and implements a technological innovation: technological context, organizational context, and environmental context (Tornatzky et al., 1990).

Unified Theory of Acceptance and Use of Technology (UTAUT) - This theory is developed based on four pillars that play a significant role in the acceptance of the user and the usage behavior: expectation of performance, expectation of effort, social influence and facilitating conditions (Venkatesh et al., 2003).

\section{Factors that influence cloud computing adoption}

According to Ferreira and Moreira (2012), the main advantages of using cloud computing is related to the economy, including the spending on hardware, software and IT services support, followed by the increased computing power that cloud computing can provide. In the last decade, IT researchers have been applying the different frameworks for understanding technology adoption as the ones mentioned above, in an attempt to identify which are the drivers for the adoption of cloud computing by organizations (Ray, 2016). The most prominent of these studies referenced by Ray (2016) can be seen in Table 1.

Table 1. Articles of Cloud Computing Adoption Using Frameworks

\begin{tabular}{|c|c|c|}
\hline Author & Theory & Description \\
\hline Alshamaila et al. (2013) & TOE and DoI & $\begin{array}{l}\text { An exploratory study from } 15 \text { different SMEs in the Northeast } \\
\text { of England to understand the adoption of cloud computing in } \\
\text { the region. }\end{array}$ \\
\hline Borgman et al. (2013) & TOE & $\begin{array}{l}\text { An investigation over the factors influencing cloud computing } \\
\text { adoption and conceptualize how IT governance structures and } \\
\text { processes moderate these factors. }\end{array}$ \\
\hline Buavirat et al. (2019) & TAM & $\begin{array}{l}\text { Study based on the TAM framework, shows the adoption of } \\
\text { cloud computing technology for the deployment of e- } \\
\text { government, also known as G-Cloud, in Thailand. }\end{array}$ \\
\hline Gangwar et al. (2015) & $\begin{array}{l}\text { TOE and } \\
\text { TAM }\end{array}$ & $\begin{array}{l}\text { Using TOE and TAM to analyze the direct impact on cloud } \\
\text { computing adoption over } 280 \text { companies in IT, } \\
\text { manufacturing, and finance sectors in India. }\end{array}$ \\
\hline Hsu et al. (2014) & TOE and DoI & $\begin{array}{l}\text { Uses TOE and DoI frameworks to develop a cloud service } \\
\text { adoption model that deals with not only adoption intention, } \\
\text { but also pricing mechanisms and deployment models. }\end{array}$ \\
\hline Kajiyama et al. (2017) & TAM & $\begin{array}{l}\text { This study uses the TAM framework to analyze the adoption } \\
\text { of cloud computing in high-tech industries in Southern } \\
\text { California. }\end{array}$ \\
\hline Nedev (2014) & TOE & $\begin{array}{l}\text { TOE is used to explore the factors that could influence the } \\
\text { Cloud adoption in a case of study in a large multinational } \\
\text { company, using information gathered from interviews with IT } \\
\text { managers. }\end{array}$ \\
\hline
\end{tabular}


After analyzing the factors mentioned in the literature regarding the adoption of cloud computing technology by organizations, it is possible to observe (Table 2) that the most prominent factors can be organized into four different categories related to technical, organizational, environmental, and cost aspects (Ray, 2016).

Table 2. Cloud Adoption Factors and their Categories

\begin{tabular}{|c|c|}
\hline Categories & Factors \\
\hline \multirow{4}{*}{ Cost } & Adoption, Migration and Acquisition Cost \\
\hline & Customization \\
\hline & Uncertainty \\
\hline & $\begin{array}{l}\text { Cost of Data Confidentiality and Availability } \\
\text { Loss }\end{array}$ \\
\hline \multirow{5}{*}{ Technical } & Complexity of Current Systems \\
\hline & Compatibility with Current Systems \\
\hline & Scalability \\
\hline & Availability and Accessibility \\
\hline & Security \\
\hline \multirow{5}{*}{ Organizational } & Top Management Support \\
\hline & Firm Size \\
\hline & Skill of IT Resources \\
\hline & Employee Buy-in \\
\hline & Innovative Culture \\
\hline \multirow{4}{*}{ Environmental } & Industry Adoption \\
\hline & Competitor Pressure \\
\hline & Regulatory Concerns \\
\hline & Vendor Expertise/ Availability \\
\hline
\end{tabular}

\section{Methodology}

Based on the literature review we conducted a qualitative exploratory study using the Delphi method (Schmidt, 1997) with cloud computing experts, to understand the factors that are critical for the adoption of cloud computing in the current worldwide pandemic of the new coronavirus. Delphi method is appropriate when the available knowledge is unclear given and a consensus from experts' opinions are important to enhance that knowledge (Keeney, Hasson \& McKenna, 2001).

\section{Delphi Method}

The Delphi method was first used in the 1950s by RAND Corporation, during a US-sponsored military project. This project sought to obtain consensus from a group of experts, from the point of view of a Soviet strategic planner, on what would be the number of atomic bombs needed to reduce the production of ammunition by a certain amount, targeting US industries (Dalkey \& Helmer, 1963). Delphi method consists of iterative rounds of questions where expert opinions are gathered until a consensus is reached (Okoli \& Pawloski, 2004). It usually involves two or three rounds of questions, which through the classification of the items answered and the frequency distribution, the level of agreement among the experts is computed (Goodman, 1987). The Delphi method can be described by the following activities (Barrios et al., 2021; Dalkey \& Helmer, 1963; Goodman, 1987; Marques \& Freitas, 2018):

At first, questionnaire is elaborated (Q1), and experts are chosen and invited to participate in the research. After receiving the first round of responses to the first questionnaire (Q1), these 
responses are analyzed. Based on those results and if a second round of responses is necessary because a consensus was not reach in the first round, a second questionnaire (Q2) is prepared and sent to the participants, along with feedback with the results from the first round. As soon as the responses to the second round are received, they are again analyzed. The model is repeated by inserting questionnaires (QN) with the respective analyzes, aiming to find if a consensus has been reached among the participants. Finally, the final report is written with the research conclusions.

Although there is no rule that determines the size and number of groups of experts (or panels), as this varies according to the nature of the study to be carried out, it usually involves between ten and eighteen experts. The experts on the panel must be impartial so that the information obtained reflects current knowledge or perceptions and they should also be experts on the topic (Keeney, Hasson \& McKenna, 2001; Okoli \& Pawloski, 2004).

As in other qualitative approaches, the Delphi method does not need to guarantee the representativeness of the statistical samples because this is a group decision mechanism to reach a group consensus (Okoli \& Pawloski, 2004). In addition to the panel size, another aspect to be considered is its heterogeneity, which depends on the project objective, selected design, and time frame for data collection (Keeney et al., 2001).

As suggested earlier, the goal of the Delphi method is to achieve a high degree of consensus among the participating experts. This leads to another important decision, how to define the concept of "degree of consensus"? For this, the agreement rates using statistics such as the Kendall coefficient of agreement (W) or the standard Pearson correlation coefficient ${ }^{\circledR}$ can be considered to ensure a rigorous evaluation of the classifications (Keil et al., 2013).

Table 3. Kendall's W Values Interpretation

\begin{tabular}{|l|l|l|}
\hline $\mathbf{W}$ & Interpretation & Confidence in Ranks \\
\hline 0.1 & Very weak agreement & None \\
\hline 0.3 & Weak agreement & Low \\
\hline 0.5 & Moderate agreement & Fair \\
\hline 0.7 & Strong agreement & High \\
\hline 0.9 & Unusually strong agreement & Very High \\
\hline
\end{tabular}

Regarding the degree of consensus, for this study, we chose to adopt a Kendall W value greater than 0.5 , which represents a high agreement (satisfactory result). However, if this value is not reached, and the repetition of iterations results in similar Kendall W values, Schmidt (1997) argues that the process should be closed. The fact that the panel members obtain a high level of consensus by itself does not determine the convergence between the different rounds. Thus, it is important to consider the Spearman's correlation coefficient between the results of the successive rounds. These two coefficients measure not only the experts' agreement within a round, but also the convergence given by the correlation between successive rounds (Santos \& Amaral, 2004). Spearman's correlation coefficient, $r$, can assume a range of values between 1 to +1 . A value of 0 indicates that there is no association between the variables while a value greater than 0 indicates a positive association. A negative value indicates a negative association between variables (Satue et al., 2013). After each round of questions and the respective analysis of responses, it is necessary to consider whether a new round can generate greater consensus (Kalaian \& Kasim, 2012). 


\section{Questionnaire}

According to Schmidt (1997), the ideal size for the list of items to be classified by the experts in this stage would be a minimum of 10 and a maximum of 20. For the elaboration of the questionnaire, an online tool called Survio was used, which allows a ranking type of responses. At this stage, the questionnaire (in English) was composed of three parts. The first part contains six questions regarding demographic information about the participants (Experts):

- What gender do you identify as?

- What is the highest degree or level of education you have completed?

- Where are you located? (Country)

- How many years of experience do you have in IT?

- How long have you been working with cloud computing?

- In which specialty below do you identify yourself the most?

The second part with just one question about cloud computing perception:

- $\quad$ Do you believe that the new pandemic coronavirus has changed the way companies think about cloud computing?

In the third part, the respondents were asked to classify the 18 factors, placing in order of importance, where first place is the most important and the 18th the least important one.

- What are the most relevant factors for the decision to adopt cloud computing in organizations at the current time of the new coronavirus pandemic?

The selection of professionals specialized in the subject, as well as the invitation to participate in the survey, was carried out through direct contacts at the professional social network LinkedIn. The invitation to participate in this study was sent to over 50 professionals of different genders, nationalities, company sizes and economic sectors, who met the following criteria: (i) have more than five years of experience in Information Technology and (ii) have at least one year of experience in Cloud Computing. The final panel was formed by 11 professionals specialized in the subject. More information about the experts who made up the panel and details about the questionary can be found in the Appendix A.

Following the model, during March 25 to May 12, 2021, an online survey was carried out to pursue a consensus on what would be the critical factors for cloud computing adoption during the current worldwide pandemic of the new coronavirus. For this purpose, a questionnaire based on the grouping of 4 categories and their 18 factors identified by Ray (2016) was sent to experts in cloud computing, to rank such factors by order of importance.

\section{First round}

The first round of questions started on March 25, 2021 until April 10, 2021. The 11 experts responded to the first round, which corresponds to a $100 \%$ response rate. During the first-round questionnaire, the only means of contact with the experts was by email, with no prior communication with the panel members. The open-source GNU PSPP software was used to perform data processing and statistical analysis of the sample. After the analysis of the first round, the Kendall W value obtained was 0.48, which according to Schmidt (1997), indicates a weak agreement. In addition, $82 \%$ of experts said they believe the coronavirus pandemic has changed the way companies think about cloud computing technology. 
Table 4. Round 1 Statistical Data

\begin{tabular}{|l|l|l|l|l|l|l|}
\hline Ranking & Factors & $\mathbf{N}$ & Std. Dev. & Min. & Max. & Mean \\
\hline $1^{\circ}$ & Adoption, Migration and Acquisition Cost & 11 & 3.07 & 1 & 11 & 4.27 \\
\hline $2^{\circ}$ & Availability and Accessibility & 11 & 3.75 & 1 & 11 & 4.64 \\
\hline $3^{\circ}$ & Scalability & 11 & 4.28 & 1 & 13 & 5.09 \\
\hline $4^{\circ}$ & $\begin{array}{l}\text { Cost of Data Confidentiality and Availability } \\
\text { Loss }\end{array}$ & 11 & 2.38 & 3 & 10 & 5.36 \\
\hline $5^{\circ}$ & Security & 11 & 4.14 & 1 & 14 & 6.18 \\
\hline $6^{\circ}$ & Customization & 11 & 5.27 & 1 & 18 & 7.73 \\
\hline $7^{\circ}$ & Uncertainty & 11 & 5.62 & 2 & 18 & 7.82 \\
\hline $8^{\circ}$ & Compatibility with Current Systems & 11 & 3.51 & 3 & 13 & 8.09 \\
\hline $9^{\circ}$ & Complexity of Current Systems & 11 & 3.13 & 4 & 14 & 8.73 \\
\hline $10^{\circ}$ & Top Management Support & 11 & 3.77 & 1 & 14 & 9.27 \\
\hline $11^{\circ}$ & Innovative Culture & 11 & 4.81 & 1 & 16 & 9.82 \\
\hline $12^{\circ}$ & Industry Adoption & 11 & 4.55 & 4 & 16 & 11.09 \\
\hline $13^{\circ}$ & Skill of IT Resources & 11 & 3.27 & 7 & 17 & 11.91 \\
\hline $14^{\circ}$ & Competitor Pressure & 11 & 4.65 & 3 & 17 & 12.36 \\
\hline $15^{\circ}$ & Firm Size & 11 & 2.45 & 9 & 17 & 13.00 \\
\hline $16^{\circ}$ & Employee Buy-in & 11 & 1.57 & 13 & 18 & 14.64 \\
\hline $17^{\circ}$ & Vendor Expertise/ Availability & 11 & 5.02 & 5 & 18 & 15.00 \\
\hline $18^{\circ}$ & Regulatory Concerns & 11 & 2.10 & 11 & 18 & 16.00 \\
\hline Spearman r & & & & & 0.433 \\
\hline Kendall's W & & & & & 0.485 \\
\hline
\end{tabular}

Given the low value of Kendall's W resulting from the first round, it was decided to carry out another round to try to improve the degree of consensus among experts.

Table 5. Kendall's W Coefficient Result of the First Round

\begin{tabular}{|l|l|}
\hline \multicolumn{2}{|l|}{ Test Statistics } \\
\hline $\mathrm{N}$ & 11 \\
\hline Kendall's W & 0.48 \\
\hline Chi-Square & 90.67 \\
\hline Df & 17 \\
\hline Asymp. Sig. & 0.000 \\
\hline
\end{tabular}

\section{Second round}

The second round of questions went from April 29, 2021 to May 12, 2021, and all the 11 panel members who had participated in the first Round participated in the second round, which corresponds to a $100 \%$ response rate. During the second questionnaire, the only means of contact was the e-mail. For the second round, the cloud computing adoption factors were presented, ordered according to the average obtained in the first round in addition to informing that the objective of taking another round would be to increase consensus among experts. In order to better understand what has changed in the perception of companies in relation to cloud computing technology, two more questions were also asked to the experts in this second round:

- Do you identify any other important factors for adopting cloud computing that are not on this list?

- What do you think has changed in the way companies think about cloud computing? 
After the analysis of the second round, the Kendall's W value obtained was 0.76, which according to Schmidt (1997), indicates a Strong Agreement.

Table 6. Kendall's W Coefficient Result of the Second Round

\begin{tabular}{|l|l|}
\hline \multicolumn{2}{|l|}{ Test Statistics } \\
\hline $\mathrm{N}$ & 11 \\
\hline Kendall's W & 0.76 \\
\hline Chi-Square & 142.70 \\
\hline Df & 17 \\
\hline Asymp. Sig. & 0.000 \\
\hline
\end{tabular}

Given the strong agreement observed in Kendall's W supplemented with Spearman's correlation coefficient after analysis of the second-round data, there is no need for a new round of questions with the experts (Schmidt, 1997). The classification of the main factors for the adoption of cloud computing technology during the pandemic of the new coronavirus after the second round is as follows:

Table 7. Round 2 Statistical Data

\begin{tabular}{|c|c|c|c|c|c|c|}
\hline Ranking & Factors & $\mathbf{N}$ & Std. Dev. & Min. & Max. & Mean \\
\hline $1^{\circ}$ & Adoption, Migration and Acquisition Cost & 11 & 1.12 & 1 & 4 & 1.64 \\
\hline $2^{\circ}$ & Availability and Accessibility & 11 & 2.17 & 2 & 9 & 3.09 \\
\hline $3^{\circ}$ & Scalability & 11 & 1.80 & 2 & 8 & 3.64 \\
\hline $4^{\mathrm{o}}$ & $\begin{array}{l}\text { Cost of Data Confidentiality and Availability } \\
\text { Loss }\end{array}$ & 11 & 2.46 & 1 & 11 & 4.64 \\
\hline $5^{\circ}$ & Security & 11 & 3.34 & 1 & 13 & 5.82 \\
\hline $6^{\circ}$ & Customization & 11 & 3.81 & 4 & 15 & 7.09 \\
\hline $7^{\circ}$ & Top Management Support & 11 & 2.83 & 1 & 11 & 8.27 \\
\hline $8^{\circ}$ & Compatibility with Current Systems & 11 & 1.91 & 5 & 11 & 8.36 \\
\hline $9^{\circ}$ & Complexity of Current Systems & 11 & 1.54 & 7 & 12 & 9.18 \\
\hline $10^{\circ}$ & Uncertainty & 11 & 4.00 & 6 & 18 & 9.27 \\
\hline $11^{\circ}$ & Innovative Culture & 11 & 3.21 & 5 & 18 & 10.55 \\
\hline $12^{\circ}$ & Industry Adoption & 11 & 3.04 & 2 & 12 & 10.73 \\
\hline $13^{\circ}$ & Competitor Pressure & 11 & 3.14 & 4 & 15 & 12.64 \\
\hline $14^{\circ}$ & Skill of IT Resources & 11 & 2.05 & 8 & 17 & 13.00 \\
\hline $15^{\circ}$ & Firm Size & 11 & 1.01 & 12 & 16 & 14.73 \\
\hline $16^{\circ}$ & Vendor Expertise/ Availability & 11 & 4.30 & 5 & 17 & 15.09 \\
\hline $17^{\circ}$ & Employee Buy-in & 11 & 0.75 & 14 & 17 & 15.82 \\
\hline $18^{\circ}$ & Regulatory Concerns & 11 & 1.29 & 14 & 18 & 17.45 \\
\hline \multicolumn{6}{|c|}{ Spearman $\mathrm{r}$} & 0.739 \\
\hline \multicolumn{6}{|c|}{ Kendall's W } & 0.763 \\
\hline
\end{tabular}

\section{Results and Discussion}

Data analyses show that the panel formed by professionals with knowledge on the topic under study achieved a strong agreement on the opinions regarding the ranking, in addition it is important to highlight that few experts totally agreed with the order resulting from the scores obtained on the first research round. Another fact to be highlighted was the strong convergence of opinions between the two rounds, which can be seen in Table 7, where there were no changes 
in the positions of the first six factors proposed. This may be due to the Delphi methodology allowing experts to check the ranking order resulting from the first round and after performing a self-analysis, changing or not the perceptions about the most important factors. The most prominent factor in both rounds was "Adoption, Migration and Acquisition Cost". An organization that wants to migrate to the cloud needs to better understand and compare "the current cost of maintenance of the system (on-premises)" (Ray 2016, p. 17) against "the cost of set up, subscription and maintenance of the new cloud system" (p. 17). The second most important factor in the experts' opinion was "Availability and Accessibility", which according to Ray (2016), companies that aim to migrate to the cloud need to seek answers to the questions: "How critical is the application in terms of its need? to be available and accessible?" (p. 17) and "What kind of redundancy measures does the current system have?" (p. 17), thinking about their on-premises systems, and "Can the cloud-based vendor assures meeting the current need in terms of system availability and accessibility?" (p. 17) thinking about their systems in the cloud. "Scalability" was in third place among the factors most voted by the experts in both rounds. The analysis that the company needs to make of this factor, according to Ray (2016) is to compare "How easily can the current system grow and scale with respect to the business needs" (p. 17) against "How easily is to grow the application in the cloud" (p. 17). In addition to the first three factors previously mentioned, we can highlight another important factor that changed its position after the second round. On the seventh place in the final round was the factor "Top Management Support", which in the first round was in tenth place. For this factor it is important to understand "how well does the current system perform according to the current team of top executives", "how knowledgeable are the top executives in terms of the benefits and risks of moving to cloud" (Ray 2016, p. 17) and if "is there at least 1 top executive ready to be the project sponsor" (p. 17).

Table 8. Comparison of the Classification Between Rounds

\begin{tabular}{|c|c|c|c|c|c|}
\hline Categories & Factors & $\begin{array}{l}\text { Round } 1 \\
\text { Mean }\end{array}$ & $\begin{array}{l}\text { Round } \\
1 \text { Rank }\end{array}$ & $\begin{array}{l}\text { Round } \\
2 \text { Mean } \\
\end{array}$ & $\begin{array}{l}\text { Round } \\
2 \text { Rank }\end{array}$ \\
\hline Cost & Adoption, Migration and Acquisition Cost & 4,27 & $1^{\mathrm{o}}$ & 1,64 & $1^{\mathrm{o}}$ \\
\hline Technical & Availability and Accessibility & 4,64 & $2^{\circ}$ & 3,09 & $2^{\circ}$ \\
\hline Technical & Compatibility with Current Systems & 8,09 & $8^{\circ}$ & 8,36 & $8^{\circ}$ \\
\hline Environmental & Competitor Pressure & 12,36 & $14^{\circ}$ & 12,64 & $13^{\circ}$ \\
\hline Technical & Complexity of Current Systems & 8,73 & $9^{\circ}$ & 9,18 & $9^{\circ}$ \\
\hline Cost & Cost of Data Confidentiality \& Availability Loss & 5,36 & $4^{\circ}$ & 4,64 & $4^{\circ}$ \\
\hline Cost & Customization & 7,73 & $6^{\circ}$ & 7,09 & $6^{\circ}$ \\
\hline Organizational & Employee Buy-in & 14,64 & $16^{\circ}$ & 15,82 & $17^{\circ}$ \\
\hline Organizational & Firm Size & 13,00 & $15^{\circ}$ & 14,73 & $15^{\circ}$ \\
\hline Environmental & Industry Adoption & 11,09 & $12^{\circ}$ & 10,73 & $12^{\circ}$ \\
\hline Organizational & Innovative Culture & 9,82 & $11^{\circ}$ & 10,55 & $11^{\circ}$ \\
\hline Environmental & Regulatory Concerns & 16,00 & $18^{\circ}$ & 17,45 & $18^{\circ}$ \\
\hline Technical & Scalability & 5,09 & $3^{\circ}$ & 3,64 & $3^{\circ}$ \\
\hline Technical & Security & 6,18 & $5^{\circ}$ & 5,82 & $5^{\circ}$ \\
\hline Organizational & Skill of IT Resources & 11,91 & $13^{\circ}$ & 13,00 & $14^{\circ}$ \\
\hline Organizational & Top Management Support & 9,27 & $10^{\circ}$ & 8,27 & $7^{\circ}$ \\
\hline Cost & Uncertainty & 7,82 & $7^{\circ}$ & 9,27 & $10^{\circ}$ \\
\hline Environmental & Vendor Expertise/ Availability & 15,00 & $17^{\circ}$ & 15,09 & $16^{\circ}$ \\
\hline \multicolumn{2}{|l|}{ Chi-Square } & \multicolumn{2}{|c|}{90,66826156} & \multicolumn{2}{|c|}{142,7001595} \\
\hline \multicolumn{2}{|l|}{ p-value } & \multicolumn{2}{|c|}{$4,61355 \mathrm{E}-12$} & \multicolumn{2}{|c|}{$6,51298 \mathrm{E}-22$} \\
\hline \multicolumn{2}{|l|}{ Kendall's W } & \multicolumn{2}{|c|}{0,484857014} & \multicolumn{2}{|c|}{0,763102457} \\
\hline \multicolumn{2}{|c|}{ Spearman $\mathrm{r}$} & \multicolumn{2}{|c|}{0,433342715} & \multicolumn{2}{|c|}{0,739412703} \\
\hline \multicolumn{2}{|c|}{ Spearman Correlation (CORREL Function Excel) } & \multicolumn{4}{|c|}{0.984529576} \\
\hline
\end{tabular}


Regarding the open question "Do you identify any other important factors for adopting cloud computing that are not on this list?", the experts pointed factors like "Flexibility to adopt new solutions"; "Customer/ Clients Pressure" and "Time to market, tooling(automation), make agile culture/devops possible". For the second open question "What do you think has changed in the way companies think about cloud computing?" it is possible to relate the factors of adoption of cloud computing with a change in the organizations' view about this technology. Scalability, Availability and Accessibility are the factors mentioned by the experts: "during the pandemic some customers finally noticed how easy and cheap it is to maintain and expand solutions over cloud infrastructure, as almost everything can be managed and expanded remotely by experts" and "information sharing for the most accessible team combined with remote access". According to Ray (2016), such factors demonstrate the concern of organizations in understanding how easily the cloud provider can scale the application for them, or even knowing whether the provider can guarantee the fulfillment of the current needs in terms of systems availability and accessibility.

Is it possible to identify the factors Competitor Pressure and Industry Adoption in these expert comments: "Covid forced many to accelerate [cloud computing] adoption. Now that many have more maturity and more companies loved it, this brings more comfort for many others to adopt" and "more companies adopting, that puts pressure and make the competition". Such factors show the concern of organizations in knowing to what extent the use of cloud-based applications has penetrated the sector in which they are inserted, as well as knowing if their main competitors have already adopted the cloud and if they are seeing benefits from this adoption (Ray, 2016).

Security is another the factor suggested by the experts and that can be seen in: "I believe that the biggest concern before was the maturity and security that the cloud platform could offer and that actually goes beyond" and "during the pandemic, they realized that cloud would be the safer and fast way to keep their projects running, accomplish SLA's already set on new contracts or deployments and it would be the safer way for employees". According to Ray (2016), this factor refers to the concern of organizations regarding the ability to replicate the same security measures they already have in their on-premises environments to the cloud one, as well as knowing what types of security mechanisms cloud computing providers have.

Innovative culture and uncertainty are the factors that can be highlighted in these comments: "I would say that companies had to adapt very quickly during the pandemic. Not only to keep the business running, but also as a way to take advantage of to accelerate projects that had been shelved for some time. I think that companies are finally seeing more of the potential of cloud computing" and "perhaps it has changed the timing to a move to the cloud. Those that would do this in the near future, anticipated this change to take advantage of the opportunity and the competition". Here the factors reference organizations' concern to understand how cloud-based work environment can be seen as an innovative way of doing things, and if cloudbased applications can be changed quickly as well as what would be the cost of such a reconfiguration (Ray, 2016).

\section{Conclusions}

Although migration to the cloud is a global trend for organizations looking to improve performance or just maintain working conditions, it is evident that it is extremely important for companies to present dynamic and adaptable solutions in various aspects and situations, even more so during this current situation to cope with the pandemic of the new coronavirus where each challenge to be faced requires its own solution such as organizing and maintaining the 
guideline of a company even without meeting in person or going to the office. Returning to the questions initially presented:

(1) What are the most relevant factors for the decision of cloud computing adoption in organizations in the current pandemic of the new coronavirus?

It can be concluded that due to the strong agreement in the last round, this empirical study shows that the ordering of the six most important factors for the adoption of cloud computing technology showed great coherence through Spearman's correlation coefficient because they occupy the same positions in the two rounds. In this case, the six most important factors for the panel of experts that allow us to answer the research question are: (1) Adoption, Migration and Acquisition Cost; (2) Availability and Accessibility; (3) Scalability; (4) Cost of Data Confidentiality and Availability Loss; (5) Security; (6) Customization.

(2) How do the pandemic crisis impact cloud computing adoption?

It is possible to observe that the pandemic directly impacted the perception of companies in relation to cloud computing technology and that factors linked to "uncertainties about the future and innovation" such as: Scalability; Availability and Accessibility, Competitor Pressure; Industry Adoption, Security, Innovative Culture and Uncertainty were the most highlighted by specialists in this regard. Therefore, it is extremely important that companies present fast, dynamic and adaptable solutions in different aspects and situations, mainly due to the new coronavirus pandemic, where for each challenge to be faced, an innovative solution is needed to respond the most quickly and precisely as possible to the needs of your customers and / or users.

Although cloud computing technology is growing rapidly and has proven to be a great ally for companies in this time of pandemic, the biggest concern on the part of organizations is related to its cost. Furthermore, it should not be considered just a single isolated factor for the decision to adopt cloud computing but check the pros and cons of the main factors that were highlighted in this article. Indeed, strategic concern is fundamental to adapting organizational processes and structures to meet demands and obtain the greatest value from change. Finally, it is clear that organizations and decision makers will face considerable challenges if they are to capture the full potential of this technology.

One of the limitations that can be mentioned in the development of this study is related to the number of specialists willing to collaborate and answer the questionnaires proposed in the research. This is because this factor directly influences the number of panels that can be developed simultaneously on the subject studied, which would make it possible to compare not only the experts' responses, but also between the different panels. Another limitation concerns the coverage of the countries in the sample. Although the study covers the perspective of experts from four different countries, the representativeness can be improved in a future study, expanding the number of countries in the sample.

Future research may address two other areas. First, comparative studies can investigate additional characteristics regarding the sector of economic activity of companies that intend to adopt cloud computing technology and thus verify whether there are different perceptions. Second, with additional data over time, future research could examine the real impact of a migration to the post-pandemic cloud and thus analyze whether there is a gradual shift in the adoption factors of the technology. 


\section{References}

Alashhab, Z. R., Anbar, M., Singh, M. M., Leau, Y., Al-Sai, Z. A., \& Alhayja'a, S. A. (2021). Impact of coronavirus pandemic crisis on technologies and cloud computing applications. Journal of Electronic Science and Technology, 19(1). https://doi.org/10.1016/j.jnlest.2020.100059

Alshamaila, Y., Papagiannidis, S., \& Li, F. (2013). Cloud computing adoption by SMEs in the north east of England: A multi-perspective framework. Journal of Enterprise Information Management, 26(3), 250-275. https://doi.org/10.1108/1741039 $\underline{1311325225}$

Armbrust, M., Fox, A., Griffith, R., Joseph, A. D., Katz, R., Konwinski, A., Lee, G., Patterson, D., Rabkin, A., Stoica, I., \& Zaharia, M. (2010). A view of cloud computing. Communications of the ACM, 53(4), 50-58. https://doi.org/10.1145/1721654.1721672

Barrios, M., Guilera, G., Nuño, L., \& Gómez-Benito, J. (2021). Consensus in the Delphi method: What makes a decision change? Technological Forecasting and Social Change, 163. https://doi.org/10.1016/j.techfore.2020.120484

Borgman, H. P., Bahli, B., Heier, H., \& Schewski, F. (2013). Cloudrise: Exploring cloud computing adoption and governance with the TOE framework. Proceedings of the 46th Hawaii International Conference on System Sciences, 4425-4435. https://doi.org/10.1109/HICSS.2013.132

Bouziri, H., Smith, D. R. M, Descatha, A., Dab, W., \& Jean, K. (2020). Working from home in the time of COVID-19: How to best preserve occupational health? Occupational and Environmental Medicine, 77(7), 509-510. http://dx.doi.org/10.1136/oemed-2020106599

Buavirat, W., Kreesuradej, W., \& Chaveesuk, S. (2019). The framework of government cloud computing adoption with TAM in Thailand. Association for Computing Machinery, 196-200. https://doi.org/10.1145/3357419.3357458

Burgess, S., \& Sievertesen, H. (2020). Schools, skills, and learning: The impact of COVID19 on education. VOX CEPR Policy Portal. https://voxeu.org/article/impact-covid-19education

Buyya, R., Yeo C. S., \& Venugopal, S. (2008). Market-oriented cloud computing: Vision, hype, and reality for delivering IT services as computing utilities. 10th IEEE International Conference on High Performance Computing and Communications, 5 13. https://doi.org/10.1109/HPCC.2008.172

Dalkey, N., \& Helmer, O. (1963). An experimental application of the Delphi method to the use of experts. Management Science, 9(3), 458-467. https://doi.org/10.1287/mnsc.9.3.458

Davis, F. D. (1989). Perceived usefulness, perceived ease of use, and user acceptance of information technology. MIS Quarterly, 13(3), 319-340. https://doi.org/10.2307/249008

Ferreira, O., \& Moreira, F. (2012). Cloud computing implementation level in Portuguese companies. Procedia Technology, 5, 491-499. https://doi.org/10.1016/j.protcy.2012.09.054 
Fitzgerald, S., Jimenez, D., Findling, S., Yorifuji, Y., Kumar, M., Wu, L., Carosella, G., Ng, S., Parker, R., Carter, P., \& Whalen, M. (2020). IDC FutureScape: Worldwide digital transformation 2021 predictions. https://www.idc.com/getdoc.jsp?containerId=US46880818

Gangwar, H., Date, H., \& Ramaswamy, R. (2015). Understanding determinants of cloud computing adoption using an integrated TAM-TOE model. Journal of Enterprise Information Management, 28(1), 107-130. https://doi.org/10.1108/JEIM-08-2013$\underline{0065}$

Garrison, G., Wakefield, R. L., \& Kim, S. (2015). The effects of IT capabilities and delivery model on cloud computing success and firm performance for cloud supported processes and operations. International Journal of Information Management, 35(4), 377-393. https://doi.org/10.1016/j.ijinfomgt.2015.03.001

Gartner (2020, November 17). Gartner forecasts worldwide public cloud end-user spending to grow $18 \%$ in 2021 . https://www.gartner.com/en/newsroom/press-releases/2020-1117 -gartner-forecasts-worldwide-public-cloud-end-user-spending-to-grow-18-percentin-2021

Goodman, C. M. (1987). The Delphi technique: A critique. Journal of Advanced Nursing, 12(6), 729-734. https://doi.org/10.1111/j.1365-2648.1987.tb01376.x

Goyal, S. (2014). Public vs private vs hybrid vs community - Cloud computing: A critical review. International Journal of Computer Network and Information Security, 6(3), 20-29. https://doi.org/10.5815/ijcnis.2014.03.03

Gupta, P., Seetharaman, A., \& Raj, J. (2013). The usage and adoption of cloud computing by small and medium businesses. International Journal of Information Management, 33(5), 861-874. https://doi.org/10.1016/j.ijinfomgt.2013.07.001

Hou, T. (2021). IaaS vs PaaS vs SaaS enter the Ecommerce vernacular: What you need to know, examples \& more. https://www.bigcommerce.com/blog/saas-vs-paas-vsiaas/\#the-three-types-of-cloud-computing-service-models-explained

Hsu, P. F., Ray, S., \& Li-Hsieh, Y-Y. (2014). Examining cloud computing adoption intention, pricing mechanism, and deployment model. International Journal of Information Management, 34(4), 474-488. https://doi.org/10.1016/j.ijinfomgt.2014.04.006

Huang, C., Wang, Y., Li, X., Ren, L., Zhao, J., Hu, Y., Zhang, L., Fan, G., Xu, J., Gu, X., Cheng, Z., Yu, T., Xia, J., Wei, Y., Wu, W., Xie, X., Yin, W., Li, H., Liu, M., Xiao, ... Cao, B. (2020). Clinical features of patients infected with 2019 novel coronavirus in Wuhan, China. The Lancet, 395, 497-506. https://doi.org/10.1016/S01406736(20)30183-5

Kajiyama, T., Jennex, M., \& Addo, T. (2017). To cloud or not to cloud: how risks and threats are affecting cloud adoption decisions. Information and Computer Security, 25(5), 634-659. https://doi.org/10.1108/ICS-07-2016-0051

Kalaian, S., \& Kasim, R. M. (2012). Terminating sequential Delphi survey data collection. Practical Assessment, Research \& Evaluation, 17(5). https://doi.org/10.7275/g48qje05

Keeney, S., Hasson, F., \& McKenna, H. P. (2001). A critical review of the Delphi technique as a research methodology for nursing. International Journal of Nursing Studies, 38(2), 195-200. https://doi.org/10.1016/S0020-7489(00)00044-4 
Keil, M., Lee, H. K., \& Deng, T. (2013). Understanding the most critical skills for managing IT projects: A Delphi study of IT project managers. Information \& Management 50(7), 398-414. https://doi.org/10.1016/j.im.2013.05.005

Leavitt, N. (2009). Is cloud computing really ready for prime time? Computer 42(1), 15-20. https://10.1109/MC.2009.20

Lin, A., \& Chen, N. (2012). Cloud computing as an innovation: Perception, attitude, and adoption. International Journal of Information Management 32(6), 533-540. https://doi.org/10.1016/j.ijinfomgt.2012.04.001

Low, C., Chen, Y., \& Wu, M. (2011). Understanding the determinants of cloud computing adoption. Industrial Management \& Data Systems 111(7), 1006-1023. https://doi.org/10.1108/02635571111161262

Marinoni, G., Land, H., \& Jensen, T. (2020). The Impact of COVID-19 on higher education around the world. International Association of Universities Global Survey Report. https://www.iau-aiu.net/IMG/pdf/iau_covid19 and he survey_report_final_may 2020.pdf

Marques, J. B. V., \& Freitas, D. (2018). The Delphi method: Characterization and potentialities for educational research. Pro-Posições, 29(2), 389-415. https://doi.org/10.1590/1980-6248-2015-0140

Mell, P., \& Grance, T. (2011). The NIST definition of cloud computing. NIST Special Publication, 800-145.

Melo, A. S., Sobral, A. I. G. P., Marinho, M. L. M., Duarte, G. B., Vieira, A. A., \& Sobral, M. F. F. (2021). The impact of social distancing on COVID-19 infections and deaths. Tropical Diseases, Travel Medicine and Vaccines, 7(12). https://doi.org/10.1186/s40794-021-00137-3

Microsoft Azure (2021). What are public, private, and hybrid clouds? https://azure.microsoft.com/en-us/overview/what-are-private-public-hybrid-clouds/

Nedev, S. (2014). Exploring the factors influencing the adoption of cloud computing and the challenges faced by the business. Enquiry - The ACES Journal of Undergraduate Research, 5(1). http://research.shu.ac.uk/aces/enquiry/index.php/enquiry/article/ view/48

Oliveira, T. \& Martins, M. F. (2011). Literature review of information technology adoption models at firm level. Electronic Journal Information Systems Evaluation, 14(1), 110 121. https://academic-publishing.org/index.php/ejise/article/view/389

Pardeshi, V. (2014). Cloud computing for higher education institutes: Architecture, strategy and recommendations for effective adaptation. Procedia Economics and Finance, 11, 589-599. https://doi.org/10.1016/S2212-5671(14)00224-X

Ray, D. (2016). Cloud adoption decisions: Benefitting from an integrated perspective. The Electronic Journal Information Systems Evaluation, 19(1), 3-21. https://academicpublishing.org/index.php/ejise/article/view/168

Rogers, E. M. (1995). Diffusion of innovations (4th edition). Free Press.

Satue, M., Garcia-Martin, E., Fuertes, I., Otin, S., Alarcia, R., Herrero, R., Bambo, M. P., Pablo, L. E., \& Fernandez, F. J. (2013). Use of fourier-domain OCT to detect retinal 
nerve fiber layer degeneration in Parkinson's disease patients. Eye, 27, 507-514. https://doi.org/10.1038/eye.2013.4

Santos, L., \& Amaral, L. (2004). Estudos Delphi com Q-Sort sobre a web: A sua utilização em sistemas de informação. Associação Portuguesa de Sistemas de Informação (APSI). http://hdl.handle.net/1822/2280

Schmidt, R. C. (1997). Managing Delphi surveys using nonparametric statistical techniques. Decision Science,s 28(3). 763-774. https://doi.org/10.1111/j.15405915.1997.tb01330.x

Schneider, S., \& Sunyaev, A. (2016). Determinant factors of cloud-sourcing decisions: Reflecting on the IT outsourcing literature in the era of cloud computing. Journal of Information Technology, 31, 1-31. https://doi.org/10.1057/jit.2014.25

Sultan, N. (2010). Cloud computing for education: A new dawn? International Journal of Information Management, 30(2), 109-116. https://doi.org/10.1016/j.ijinfomgt.2009.09.004

Tornatzky, L. G. \& Fleischer, M. (1990). The processes of technological innovation. Lexington Books.

Vaquero, L. M., Merino, L., Caceres, J. \& Lindner, M. (2009). A Break in the clouds: Towards a cloud definition. Computer Communication Review, 39 (1), 50-55. https://doi.org/10.1145/1496091.1496100

Venkatesh, V., Morris, M., Davis, G. \& Davis, F. (2003). User acceptance of information technology: Toward a unified view. MIS Quarterly, 27(3), 425-478. https://doi.org/10.2307/30036540

World Health Organization (2021). WHO Coronavirus disease (COVID-19) dashboard. https://covid19.who.int

Worldmeters (2021). COVID-19 Corona virus pandemic. https://www.worldometers.info/ coronavirus/

\section{Authors' Biographies}

Rodolfo Vareshi, MSc. is a Professional with $12+$ years of experience in Information Technology as a Business Analyst, Project Manager, Software Engineer and Cloud Architect. He specializes in in agile projects, serverless, cloud architecture, microservices, software development, and project management. He has a MSc in Information Systems Management from Lisbon School of Economics and Management (ISEG), a Postgraduation in

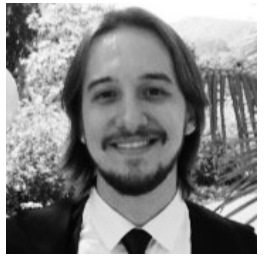
Business Economics from Fundação Getulio Vargas (FGV), and degree in Information Systems from Mackenzie University.

Winnie Ng Picoto, Ph.D. is master's Professor at Lisbon School of Economics and Management (ISEG). She has a degree in Industrial Engineering and Management by IST, MSc in Management of Information Systems and $\mathrm{PhD}$ in Management by ISEG. She is a member of Coordination of the master's degree in Information Systems Management, Coordination of the Degree in Management and the Advance Research Center at ISEG, in

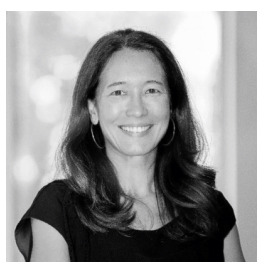
addition to having extensive professional experience working in various consultancies for the implementation of Information Systems. Her research has been published in journals such as 
the European Journal of Information Systems (EJIS), Industrial Management \& Data Systems, Journal of Organizational Computing and Electronic Commerce, Journal of Business Research, Online Journal of Applied Knowledge Management (OJAKM), among others, focusing on the areas of e-business, e-commerce, m-business, IT value and Big Data.

\section{Appendix A - Panel Composition}

\begin{tabular}{|c|c|c|}
\hline Answer Choices & Answer & Ratio \\
\hline \multicolumn{3}{|l|}{ What gender do you identify as? } \\
\hline Male & 11 & $100.0 \%$ \\
\hline \multicolumn{3}{|c|}{ What is the highest degree or level of education you have completed? } \\
\hline Bachelor's Degree & 9 & $81.8 \%$ \\
\hline Master's Degree & 2 & $18.2 \%$ \\
\hline \multicolumn{3}{|c|}{ Where are you located? (Country) } \\
\hline Australia & 2 & $18.2 \%$ \\
\hline Brazil & 7 & $63.6 \%$ \\
\hline Chile & 1 & $9.1 \%$ \\
\hline Portugal & 1 & $9.1 \%$ \\
\hline \multicolumn{3}{|c|}{ How many years of experience do you have in IT? } \\
\hline $10-12$ years & 1 & $9.1 \%$ \\
\hline $13-15$ years & 3 & $27.3 \%$ \\
\hline More than 15 years & 7 & $63.6 \%$ \\
\hline \multicolumn{3}{|c|}{ How long have you been working with cloud computing? } \\
\hline $1-3$ years & 5 & $45.5 \%$ \\
\hline More than 3 years & 6 & $54.5 \%$ \\
\hline \multicolumn{3}{|c|}{ In which specialty below do you identify yourself the most? } \\
\hline Administrator & 1 & $9.1 \%$ \\
\hline Architect & 5 & $45.5 \%$ \\
\hline Engineer & 3 & $27.3 \%$ \\
\hline Network & 2 & $18.1 \%$ \\
\hline \multicolumn{3}{|c|}{$\begin{array}{l}\text { Do you believe that the new pandemic coronavirus has changed the } \\
\text { way companies think about cloud computing? }\end{array}$} \\
\hline No & 2 & $18.2 \%$ \\
\hline Yes & 9 & $81.8 \%$ \\
\hline \multicolumn{3}{|c|}{ Size of the company where the expert works } \\
\hline Small (7-250 employees) & 1 & $9.1 \%$ \\
\hline Large (501<1000 employees) & 1 & $9.1 \%$ \\
\hline Enterprise (+1001 employees) & 9 & $81.8 \%$ \\
\hline \multicolumn{3}{|c|}{ Expert activity sector according to Overview of the S\&P } \\
\hline Communication Services & 2 & $18.1 \%$ \\
\hline Financials & 3 & $27.3 \%$ \\
\hline Industrials & 1 & $9.1 \%$ \\
\hline Information Technology & 5 & $45.5 \%$ \\
\hline
\end{tabular}

